\title{
SISTEM PENUNJANG KEPUTUSAN DALAM MENENTUKAN INSENTIF BAGI KARYAWAN MENGGUNAKAN METODE PROMETHEE
}

\author{
Aorora Mahardika ${ }^{1)}$, Sri Siswanti ${ }^{2)}$, Tri Irawati ${ }^{3)}$ \\ ${ }^{1,2)}$ Program Studi Teknik Informatika, STMIK Sinar Nusantara Surakarta \\ 3) Program Studi Komputerisasi AKuntansi, STMIk SInar Nusantara Surakarta \\ ${ }^{1)}$ chorysimadona@gmail.com, ${ }^{2)}$ syswanty@ sinus.ac.id, ${ }^{3)}$ irawati3@yahoo.co.id
}

\begin{abstract}
PT. Sami Surya Indah has 7,100 employees who provide incentive issues, in addition to the current handling of obstacles in reporting and determination of employees who deserve incentives. The current system in the Company is still using manual process where the database used is still in paper form. For that will be designed and made a decision support system to determine the incentives for employees with the method Promethee in PT. Sami Surya Indah. The purpose of this study is to design and build systems that can assist in determining the feasibility of providing incentives to prospective employees. This study also aims to apply the Promethee method for determining the feasibility of providing incentives to employees. Methods of data collection include field study and literature study. Field studies include interviews and observations. While the literature study conducted by examining the relevant literature with the problem. Designing system design using CD (Context Diagram), DFD (Data Flow Diagram) and ERD (Entity Relation Diagram), Implementation program with PHP and database MySql. The results of the functionality test shows the application is running in accordance with its function and based on the validity test of the application has been declared valid. In performing system performance testing the author uses Blackbox method.
\end{abstract}

Keywords: Decision Support System, Promethee Method, Incentive Determination

\section{PENDAHULUAN}

Insentif adalah suatu bentuk dorongan finansial kepada karyawan sebagai balas jasa perusahaan kepada karyawan atas prestasi karyawan tersebut. Insentif merupakan sejumlah uang yang ditambahkan pada upah dasar yang di berikan perusahaan kepada karyawan.

Sistem penentuan insentif bagi karyawan pada Perusahaan Sami Surya Indah yang sedang berjalan yaitu menggunakan sistem perhitungan poin. Dengan metode perhitungan poin ini apabila karyawan mempunyai poin diatas grade yang ditentukan maka karyawan tersebut berhak mendapatkan insentif dari perusahaan. Akan tetapi masalah yang muncul dari metode poin tersebut yaitu metode poin yang diterapkan oleh perusahaan tidak menerapkan nilai prioritas terhadap variabel yang dijadikan parameter untuk menghitung poin tersebut. Sehingga setiap variabel tidak memiliki tingkat prioritas. Hal tersebut menjadikan setiap kriteria yang seharusnya mempunyai bobot atau prioritas yang tinggi akan mempunyai nilai yang sama.

Berdasarkan permasalahan diatas maka penulis dalam hal ini akan membuat suatu Sistem penunjang keputusan dalam menentukan calon penerima insentif bagi karyawan. Dengan sistem yang dibangun oleh penulis ini akan memudahkan bagi Perusahaan dalam menentukan calon penerima insentif. Perusahaan akan memperoleh hasil data yang tepat dan secara cepat. 


\section{TINJAUAN PUSTAKA}

\subsection{Sistem Pendukung Keputusan}

Sistem pendukung keputusan dapat digambarkan sebagai sistem yang berkemampuan mendukung analisis ad hoc data, dan pemodelan keputusan, berorientasi keputusan, orientasi perencanaan masa depan, dan digunakan pada saatsaat yang tidak biasa (Fathansyah, 2012)

\subsection{Promethee}

Promethee adalah suatu metode penentuan urutan (prioritas) dalam analisis multikriteria. Sawicki mengungkapkan kriteria adalah definisi masalah dalam bentuk yang konkret dan kadang-kadang dianggap sebagai sasaran yang akan dicapai (Turban, 2005)

\section{a. Kriteria Quansi / tipe II (Quansi Kriteria)}

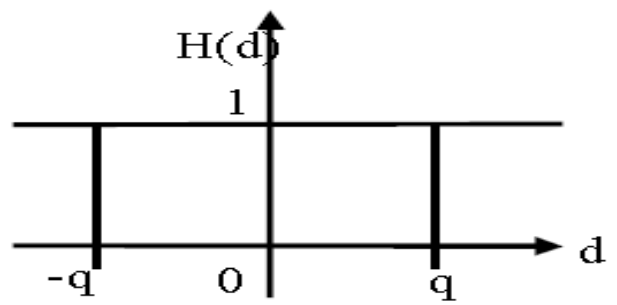

$$
\begin{aligned}
& \mathrm{H}(\mathrm{d})=0 \text { jika }-\mathrm{q} \leq \mathrm{d} \leq \mathrm{q} \\
& 1 \text { jika } \mathrm{d}<-\mathrm{q} \text { atau } \mathrm{d}>\mathrm{q}
\end{aligned}
$$

Gambar 1. Kriteria Quansi

Pada kriteria ini dua alternatif memiliki preferensi yang sama penting selama selisih atau nilai $\mathrm{H}(\mathrm{d})$ dari masing - masing alternative untuk criteria tertentu tidak melebihi nilai q dan apabila selisih hasil evaluasi untuk masing - masing alternative melebihi nilai q maka terjadi bentuk preferensi mutlak. Jika pembuat keputusan menggunakan criteria quansi, maka dia harus menentukan nilai q, dimana nilai ini dapat menjelaskan pengaruh yang signifikan dari suatu criteria. Dengan demikian q adalah merupakan nilai threshold indifference yaitu nilai dterbesar yang masih memungkinkan terjadinya indifference antar alternatif.

\section{b. Standar Insentif Karyawan}

Berdasarkan keputusan dari PT. Sami Surya Indah nilai standar calon penerima insentif adalah 70. Dari situlah untuk mengetahui calon karyawan penerima insentif, kemudian dicari nilai yang paling tertinggi dan yang paling banyak yang berhak menerima insentif.

\subsection{Penelitian Terdahulu}

Berdasarkan penelitian Ranida Pradita dan Nurul Hidayat yang berjudul Sistem Pendukung Keputusan Pemilihan Guru Berprestasi Menggunakan Metode Promethee diperoleh kesimpulan Pemilihan guru berprestasi dengan menggunakan sistem yang dibuat/dikembangkan ini, hasil perangkingan guru-guru berprestasi (dari semua peserta) jauh lebih cepat didapat dan diharapkan lebih akurat, karena sistem ini menggunakan kriteria-kriteria yang berkaitan dengan kualitas dan kuantitas prestasi para guru peserta pemilihan, serta mereduksi subyektifitas dari para penilai (Hidayat, 2013)

Berdasarkan penelitian Harry Budiharjo S, Herry Sofyan, Suparja yang berjudul Perencanaan Sistem Pendukung Pengambilan Keputusan Penerimaan Taruna Dengan Metode Promethee (Studi Kasus Seleksi Taruna Akmil) diperoleh kesimpulan: (1) Metode Promethee dapat digunakan dalam menyusun ranking calon 
taruna, yang dapat memberikan hasil yang tepat dan akurat. Karena metode ini dalam proses perankingan alternatif menggunakan data kuantitatif maupun data kualitatif. Data tersebut akan digabungkan menjadi satu dengan bobot penilaian yang telah diperoleh melalui penilaian atau survei yang dilakukan kepada para pakar. Pada metode promethee perankingan dilakukan berdasarkan tingkat dominasi antara alternatif satu dengan alternatif lainnya, semakin dominasinya besar maka akan menduduki ranking di atas. (2) Dari hasil penelitian yang telah dilakukan dengan menjadikan tiga skenario yang berbeda yaitu, skenario 1 (Base case), skenario 2 (kombinasi Base case dengan promethee), skenario 3 (metode Promethee) memberikan hasil yang berbeda. Perbedaan pada skenario 1 dengan skenario 2 pada kategori kelompok I tidak jauh berbeda namun pada kelompok II dan selanjutnya perbedaannya cukup signifikan. Ini disebabkan karena jumlah peserta pada kelompok I hanya sedikit sedangkan kelompok yang lain pesertanya cukup banyak. Untuk skenario 3 yang menggunakan metode Promethee, memberikan perbedaan yang sangat tajam. Dari peserta yang memiliki ranking ke 12 sampai 20 pada base case ternyata akan terlempar jauh menjadi ranking di bawah antara ranking 30 sampai dengan 50 pada skenario 3, demikian juga sebaliknya yang sebelumnya ranking 22 pada skenario 1 menjadi ranking 7 pada skenario 3, masih banyak lagi perbedaan yang lain. (3) Skenario 3 yang murni menggunakan metode Promethee adalah merupakan skenario yang paling tepat digunakan untuk membuat perankingan, karena akan memberikan kesempatan kepada para calon yang memiliki kelebihan pada bidang tertentu dan terbatas pada bidang yang lain. (4) Dengan program penilaian yang berbasis Web maka memudahkan kepada sub panitia untuk menyampaikan hasil penilaian yang telah dilakukan dari tiap-tiap bagian kepada admin panitia pusat. Panitia pusat juga mudah untuk mengontrol perkembangan penilaian dari masing-masing bidang setiap saat (Harry Budiharjo S, 2015)

\section{METODE PENELITIAN}

Dalam metode penelitian dilakukan pencarian suatu data dengan teknik / metode pengumpulan data, adapun jenis data yang diperlukan yaitu.

\subsection{Jenis Data}

a. Data primer

Data primer yang dibutuhkan dalam membuat sistem pendukung keputusan dalam menentukan insentif diantaranya.

- Data karyawan yang bekerja di PT.Sami Surya Indah.

- Data absensi kehadiran karyawan.

- Data nilai kedisiplinan karyawan

- Data nilai sikap karyawan

- Data nilai loyalitas karyawan

b. Data Sekunder

Data Sekunder yang dibutuhkan dalam membangun aplikasi pendukung keputusan dalam menentukan insentif karyawan diantaranya.

- Data mengenai teori pendukung keputusan yang sesuai dengan kaidah-kaidah yang berlaku dan benar.

- Data mengenai teori metode penentuan Preference Ranking Organization Method for Enrichment Evaluation.

- Data mengenai teori tentang pengertian insentif

- Data mengenai teori bahasa pemrograman berbasis web yang sesuai dengan kaidah-kaidah yang benar. 


\subsection{Metode Pengumpulan data}

Adapun metode pengumpulan data yang dilakukan antara lain.

a. Observasi

Pada tahap ini melakukan kunjungan langsung ke PT. Sami Surya Indah. Hal tersebut dilakukan dengan tujuan agar diketahui secara langsung proses penentuan calon penerima insentif bagi karyawan dengan metode yang sudah berjalan. Selanjutnya akan menyusun langkah-langkah yang sistematis dalam membuat sistem penentuan calon penerima insentif mengguakan metode Preference Ranking Organization Method for Enrichment Evaluation.

b. Wawancara

Pada tahap ini dilakukan pengumpulan data dengan wawancara, dengan cara menerapkan metode wawancara, mengajukan pertanyaan kepada bagian $\operatorname{HRD}$ (Human Resource Development). Metode dilakukan dengan lisan sehingga dijawab dengan lisan oleh pihak perusahaan atau ahli yang mempunyai kompetensi di bidang tersebut.

c. Studi Pustaka

Pada tahap ini mencari referensi pada buku-buku yang berkaitan dengan permasalahan tersebut.

\subsection{Metode Analisa Sistem}

Dalam tahap ini adalah suatu kegiatan untuk melakukan analisa terhadap alternatif atau calon penerima insentif. Dalam hal ini menggali data dari pihak perusahaan. Masalah yang dihadapi saat ini adalah proses penentuan penerima insentif yang kurang cepat dan kurang tepat. Sehingga dengan proses analisa ini dapat mengetahui kelayakan dari sistem yang telah dibangun.

\section{HASIL DAN PEMBAHASAN}

Dalam hal pembahasan akan diuraikan tentang Analisa Alternatif, Perancangan Sistem, Halaman Aplikasi, dan Pengujian Aplikasi yang akan menjadi acuan dalam pembuatan sistem ini.

\subsection{Analisa Data Dengan Promethee}

Dalam tahap ini adalah suatu kegiatan untuk melakukan analisa terhadap alternatif atau calon penerima insentif. Dalam hal ini menggali data dari pihak perusahaan. Adapun calon alternatif dapat dilihat pada Tabel 1.

Tabel 1 Analisa Calon Alternatif

\begin{tabular}{|l|l|l|}
\hline No & Nama Alternatif & Keterangan \\
\hline 1 & Ayu Triwahyuni & Humas \\
\hline 2 & Beni Riswanto & Humas \\
\hline 3 & Dion Kusnadi & Marketing \\
\hline 4 & Eka Ayu Rismawati & HRD \\
\hline 5 & Junaidi Iswanto & TU \\
\hline
\end{tabular}

a. Analisa Kriteria

Dalam tahap ini adalah suatu kegiatan untuk melakukan analisa terhadap kriteria dalam menentukan calon penerima insentif. Dalam hal ini menggali data dari pihak perusahaan. Adapun kriteria dapat dilihat pada Tabel 2 
Tabel 2 Analisa Kriteria

\begin{tabular}{|l|l|c|c|c|}
\hline No & \multicolumn{1}{|c|}{ Kriteria } & Min/Max & Type & Batas IntervalMax \\
\hline 1 & Nilai Kehadiran & $\operatorname{Max}$ & 2 & 3 \\
\hline 2 & Nilai Kedisiplinan & $\operatorname{Max}$ & 2 & 3 \\
\hline 3 & Nilai Sikap & $\operatorname{Max}$ & 2 & 3 \\
\hline 4 & Nilai Loyalitas & $\operatorname{Max}$ & 2 & 3 \\
\hline
\end{tabular}

Keterangan:

1. Nilai kehadiran

Merupakan kriteria yang di dapat dari nilai kehadiran yang diperoleh dari hasil penilaian tingkat kehadiran dari setiap karyawan

2. Nilai Kedisiplinan

Merupakan kriteria yang di dapat dari nilai kehadiran yang diperoleh dari hasil penilaian tingkat kedisplinan dari setiap karyawan

3. Nilai Sikap

Merupakan kriteria yang di dapat dari nilai kehadiran yang diperoleh dari hasil penilaian tingkat sikap dari setiap karyawan

4. Nilai Loyalitas

Merupakan kriteria yang di dapat dari nilai kehadiran yang diperoleh dari hasil penilaian tingkat loyalitas dari setiap karyawan

b. Input Nilai

Dalam tahap ini adalah suatu kegiatan untuk melakukan analisa nilai dari setiap alternatif pada kriteria yang dimiliki. Dalam hal ini menggali data dari pihak perusahaan. Adapun data nilai dapat dilihat pada tabel 3.

\section{Klasifikasi}

Tabel 3 Klasifikasi Nilai Alternatif

\begin{tabular}{|l|l|c|c|c|c|}
\hline No & \multicolumn{1}{|c|}{ Nama Alternatif } & $\begin{array}{c}\text { Nilai } \\
\text { Kedisiplinan }\end{array}$ & $\begin{array}{c}\text { Nilai } \\
\text { Kehadiran }\end{array}$ & $\begin{array}{c}\text { Nilai } \\
\text { Loyalitas }\end{array}$ & Nilai Sikap \\
\hline 1 & Ayu Triwahyuni & 75 & 86 & 80 & 79 \\
\hline 2 & Beni Riswanto & 90 & 78 & 75 & 80 \\
\hline 3 & Dion Kusnadi & 94 & 82 & 79 & 82 \\
\hline 4 & Eka Ayu Rismawati & 85 & 88 & 83 & 83 \\
\hline 5 & Junaidi Iswanto & 80 & 79 & 78 & 72 \\
\hline
\end{tabular}

Tabel klasifikasi alternatif seperti pada Tabel 3 menjelaskan tentang nama - nama calon atau alternatif calon penerima insentif dengan nilai yang melekat pada setiap calon karyawan yang nantinya akan mendapatkan insentif. Nilai pada setiap karyawan didapatkan dari hasil pengumpulan data pada setiap komponen atau kriteria dalam proses penentuan calon penerima dana insentif. Setelah memasukan nilai dengan melakukan klasifikasi, langkah selanjutnya akan dilakukan proses analisa nilai pada setiap kriteria menggunakan metode promethee.

Preferensi Type 2 (quasi)

$\mathbf{P}(\mathbf{x})$

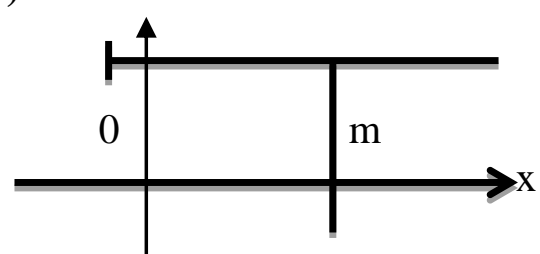

$$
P(x)=\left\{\begin{array}{l}
0, x \leq m \\
1, x>m
\end{array}\right.
$$

Gambar 2. Preferensi Type 2 (quasi) 
Keterangan :

$\begin{array}{ll}\mathrm{X} & =\text { Alternatif } \\ \mathrm{P}(\mathrm{x}) & =\text { Nilai Preferensi } \mathrm{X} \\ \mathrm{M} & =\text { Batas interval } \\ \mathrm{C} & =\text { Kriteria }\end{array}$

Nilai Prefensi (Ayu Triwahyuni dan Beni Riswanto)

- Untuk Kriteria Nilai Kedisiplinan

$$
\begin{aligned}
\mathbf{P}(\mathbf{X}) & =\mathbf{C 1}(\mathbf{A 1})-\mathbf{C 1}(\mathbf{A 2}) \\
& =75-90 \\
& =-15
\end{aligned}
$$

Berdasarkan kaidah maksimasi di peroleh : $(\mathrm{A} 1, \mathrm{~A} 2)=0$

Keterangan :

- C1 : Kriteria ke-1 (Kedispilinan)

- A1 : Karyawan Ke-1 ( Ayu tri Wahyuni)

- A2 : Karyawan Ke-2 (Beni Riswanto)

- Hasil 0, Karena hasil $\mathrm{P}(\mathrm{X})=15$, Apabila hasil $\mathrm{P}(\mathrm{X})$ kurang dari interval 3 maka hasilnya 0 . Apabila lebih dari interval 3 maka hasilnya 1 .

$$
\begin{aligned}
\mathbf{P}(\mathbf{X}) & =\mathbf{C 1}(\mathbf{A 2})-\mathbf{C 1}(\mathbf{A 1}) \\
& =90-75 \\
& =15
\end{aligned}
$$

Berdasarkan kaidah maksimasi di peroleh : $(\mathrm{A} 2, \mathrm{~A} 1)=1$

- Untuk Kriteria Nilai Kehadiran

.P(X) = C1 (A1) - C1(A2)

$=86-78$

$=8$

Berdasarkan kaidah maksimasi di peroleh : $(\mathrm{A} 1, \mathrm{~A} 2)=1$

$$
\begin{aligned}
\mathbf{P}(\mathbf{X}) & =\mathbf{C 1}(\mathbf{A 2})-\mathbf{C 1}(\mathbf{A 1}) \\
& =78-86 \\
& =-8
\end{aligned}
$$

Berdasarkan kaidah maksimasi di peroleh : $(\mathrm{A} 2, \mathrm{~A} 1)=0$

- Untuk Kriteria Nilai Loyalitas

$\mathrm{P}(\mathrm{X})=\mathrm{C1}$ (A1) $-\mathrm{C1}(\mathrm{A} 2)$

$=80-75$

$=5$

Berdasarkan kaidah maksimasi di peroleh $:(\mathrm{A} 1, \mathrm{~A} 2)=1$

$$
\begin{aligned}
\mathbf{P}(\mathbf{X}) & =\mathbf{C 1}(\mathbf{A 2})-\mathbf{C 1}(\mathbf{A 1}) \\
& =75-80 \\
& =-5
\end{aligned}
$$

Berdasarkan kaidah maksimasi di peroleh : $(\mathrm{A} 2, \mathrm{~A} 1)=0$

- Untuk Kriteria Nilai Loyalitas

$\mathbf{P}(\mathrm{X}) \quad=\mathrm{C1}(\mathrm{A} 1)-\mathrm{C1}(\mathrm{A} 2)$

$$
\begin{aligned}
& =79-80 \\
& =-1
\end{aligned}
$$

Berdasarkan kaidah maksimasi di peroleh : $(\mathrm{A} 1, \mathrm{~A} 2)=0$

$$
\begin{aligned}
\mathbf{P}(\mathbf{X}) & =\mathbf{C 1}(\mathbf{A} 2)-\mathbf{C 1}(\mathbf{A 1}) \\
& =80-79 \\
& =1
\end{aligned}
$$

Berdasarkan kaidah maksimasi di peroleh $:(\mathrm{A} 2, \mathrm{~A} 1)=0$ 


\section{Index Preferensi}

Dengan menggunakan langkah yang sama pada penilaian prefensi maka akan di dapatkan data sebagai berikut :

Index Preferensi $(\mathrm{Pi}) \mathrm{A} 1, \mathrm{~A} 2=\Sigma(\mathrm{PX}) / \Sigma \mathrm{C}$

$$
\begin{aligned}
& =(0+1+1+0) / 4 \\
& =0,50
\end{aligned}
$$

Index Preferensi $(\mathrm{Pi}) \mathrm{A} 2, \mathrm{~A} 1=\Sigma(\mathrm{PX}) / \Sigma \mathrm{C}$

$$
\begin{aligned}
& =(1+0+0+0) / 4 \\
& =0,25
\end{aligned}
$$

Dengan menggunakan langkah yang sama dengan data set yang telah ditentukan maka ringkas perhitungan akan didapatkan seperti Tabel 4.

Tabel 4 Matrik Perhitungan Pi

\begin{tabular}{|l|l|l|l|l|l|}
\hline Alternatif & A1 & A2 & A3 & A4 & A5 \\
\hline A1 & - & 0,5 & 0,5 & 0 & 0,75 \\
\hline A2 & 0,25 & - & 0 & 0,25 & 0,5 \\
\hline A3 & 0,25 & 0,75 & - & 0,25 & 1 \\
\hline A4 & 0,5 & 0,5 & 0,5 & - & 1 \\
\hline A5 & 0,25 & 0 & 0 & 0 & - \\
\hline
\end{tabular}

3. Leaving Flow

$$
\phi+(\mathrm{a})=\frac{1}{n-1} \sum \boldsymbol{p}(\mathbf{a}, \mathbf{x})
$$

Dimana :

$\boldsymbol{p}(\mathbf{a}, \mathbf{x})$ : Nilai Indeks preferensi

n : Jumlah alternatif

Sehingga :

$$
\begin{aligned}
\Phi^{+}(\mathrm{A} 1) & =(1 /(5-1))(0,5+0,5+0+0,75) \\
& =0,438 \\
\Phi^{+}(\mathrm{A} 2) & =(1 /(5-1))(0,25+0+0,25+1) \\
& =0,25 \\
\Phi^{+}(\mathrm{A} 3) & =(1 /(5-1))(0,25+0,75+0,25+1) \\
& =0,563 \\
\Phi^{+}(\mathrm{A} 4) & =(1 /(5-1))(0,5+0,5+0,5+1) \\
& =0,625 \\
\Phi^{+}(\mathrm{A} 5) & =(1 /(5-1))(0,25+0+0+0) \\
& =0,063
\end{aligned}
$$

\section{Entering Flow}

$$
\phi-(\mathrm{a})=\frac{1}{n-1} \sum p(\mathbf{x}, \mathbf{a})
$$

Dimana :

$\boldsymbol{p}(\mathbf{x}, \mathbf{a})$ : Nilai Indeks preferensi $(b, a)$

n : Jumlah alternatif

Sehingga :

$$
\begin{aligned}
\Phi(A 1) & =(1 /(5-1))(0,25+0,25+5+0,25) \\
& =0,313 \\
\Phi(A 2) & =(1 /(5-1))(0,5+0,75+0,5+0) \\
& =0,438
\end{aligned}
$$




$$
\begin{aligned}
\Phi(A 3) & =(1 /(5-1))(0,5+0+0,5+0) \\
& =0,25 \\
\Phi(A 4) & =(1 /(5-1))(0+0,25+0,25+0) \\
& =0,125 \\
\Phi(\text { A5) } & =(1 /(4-1))(0,75+5+1+1) \\
& =0,81
\end{aligned}
$$

\section{Net Flow}

Perhitungan Promethee II yaitu mencari nilai net flow atau nilai keseluruhan. Nilai net flow didapat dari pengurangan nilai leaving flow dengan nilai entering flow. Untuk mendapatkan nilai net flow dapat menggunakan persamaan sebagai berikut.

$$
\phi(a)=\phi^{+}(a)-\phi^{-}(a)
$$

Dimana :

$$
\begin{aligned}
& \phi^{+} \text {: nilai leaving flow } \\
& \phi^{-} \text {: nilai entering flow }
\end{aligned}
$$

Sehingga :

$\Phi($ A1 / Ayu Tri Wahyuni $)=0,438-0,313=0,125$

$\Phi(\mathrm{A} 2$ / Beni Riswanto $)=0,25-0,438=-0,188$

$\Phi(\mathrm{A} 3 /$ Dion Kusnaidi $)=0,563-0,25=0,313$

$\Phi($ A4 / Eka Ayu Rismawati $)=0,625-0,125=0,5$

$\Phi($ A5 / Junaidi Riswanto $)=0,063-0,813=-0,75$

c. Hasil

Berdasarkan hasil perhitungan menggunakan metode Promethee diatas dapat ditarik kesimpulan, bahwa karyawan yang layak mendapatkan dana insentif dari hasil perhitungan tersebut adalah Eka Ayu Rismawati dengan bobot net flow yang paling besar. Dimana bobot dari Eka Ayu Rismawati adalah 0,5.

\subsection{Perancangan Sistem}

a. Contex Diagram

Diagram Konteks pada Sistem Penentuan Calon Penerima Insentif ini menggambarkan sistem aliran program secara umum. Adapun gambaran context diagram seperti pada Gambar 3.

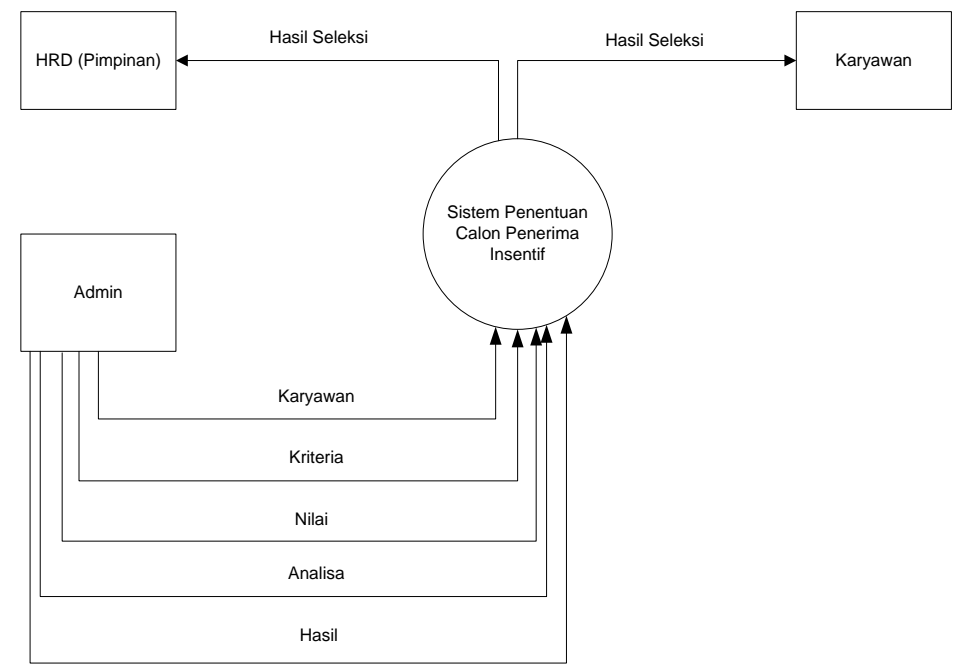

Gambar 3. Context Diagram 
b. Data Flow Diagram

Data flow diagram (Gambar 4) merupakan suatu gambaran sistem secara logika dan teknik dari penggambaran aliran data dengan menggunakan simbol-simbol tertentu

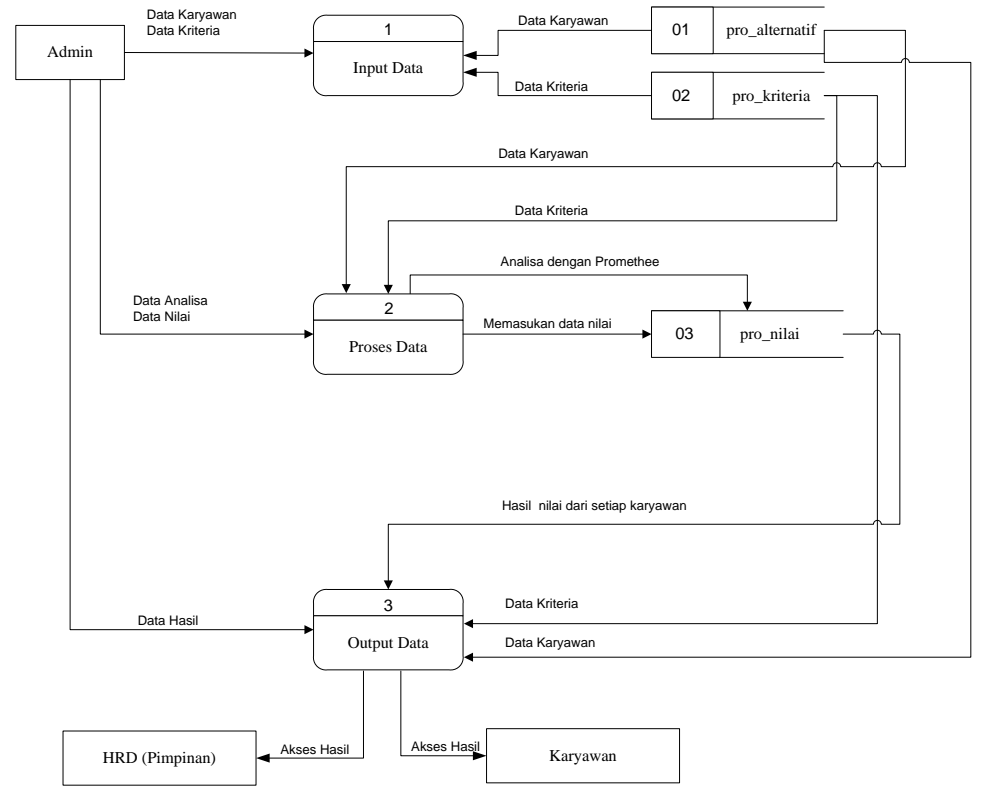

Gambar 4. Data Flow Diagram

c. Relasi Antar Tabel

Dalam aplikasi pendukung keputusan yang dibangun ini terdapat 4 buah tabel utama yang mempunyai relasi atau hubungan seperti pada Gambar 5.

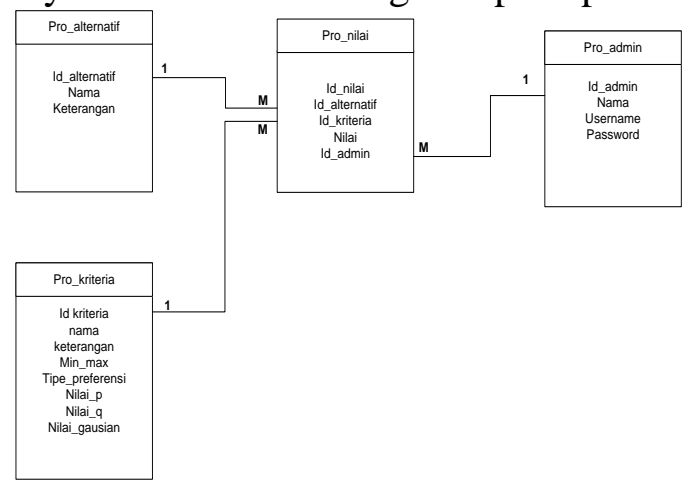

\subsection{Halaman Aplikasi}

Gambar 5. Relasi antar tabel

\section{a Form Tampil Data Alternatif}

Tampilan form tampil data alternatif (Gambar 6) ini merupakan salah satu form atau fitur tampilan dari aplikasi yang digunakan untuk menampilkan data alternatif atau data karyawan yang akan diseleksi untuk mendapatkan dana insentif.

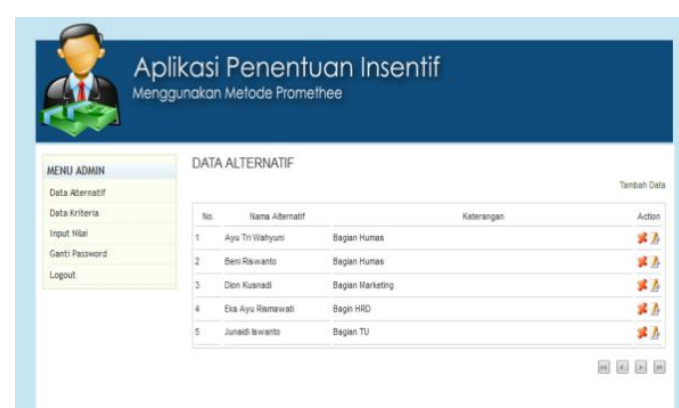

Gambar 6. Tampilan Form Tampil Data Alternatif 
b Form Tambah Data Alternatif

Tampilan form tambah data alternatif seperti pada Gambar 7, merupakan salah satu form atau fitur tampilan dari aplikasi yang digunakan untuk menambahkan data alternatif atau data karyawan yang akan diseleksi untuk mendapatkan dana insentif. Pada halaman tambah data alternatif ini terdapat beberapa fitur atau elemen yang masing-masing elemen mempunyai fungsi yang berbeda-beda.

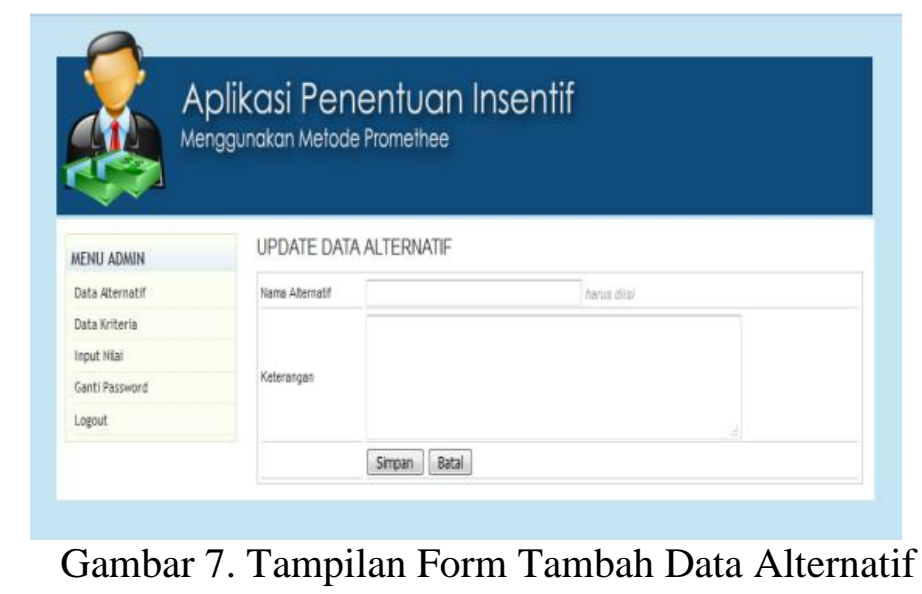

c Form Tampil Data Kriteria

Tampilan form tampil data kriteria seperti pada Gambar 8, merupakan salah satu form atau fitur tampilan dari aplikasi yang digunakan untuk menampilkan data kriteria yang telah dimasukkan ke dalam sistem aplikasi. Data kriteria yang dimaksud yaitu data yang terkait dengan proses penentuan pemberian insentif kepada karyawan.

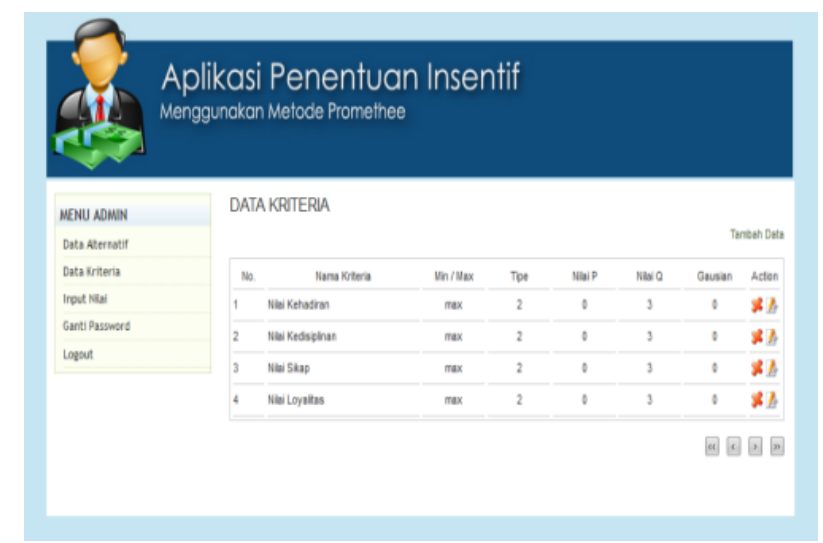

Gambar 8. Tampilan Form Tampil Data Kriteria

d Form Input Nilai

Tampilan form input nilai ini merupakan salah satu form atau fitur tampilan dari aplikasi yang digunakan untuk memasukkan data nilai dari setiap karyawan ke dalam sistem aplikasi ini. Data nilai yang dimaksud merupakan nilai dari kriteria yang dijadikan acuan dalam menentukan calon karyawan yang berhak menerima insentif. Pada halaman input nilai ini terdapat beberapa fitur atau elemen yang masing-masing elemen mempunyai fungsi yang berbeda-beda. Pada halaman ini sistem akan memasukan data yang telah diketikan oleh user. Kemudian sistem akan melakukan proses perhitungan menggunakan metode Promethee. Adapun tampilan form update data kriteria terdapat pada Gambar 9. 


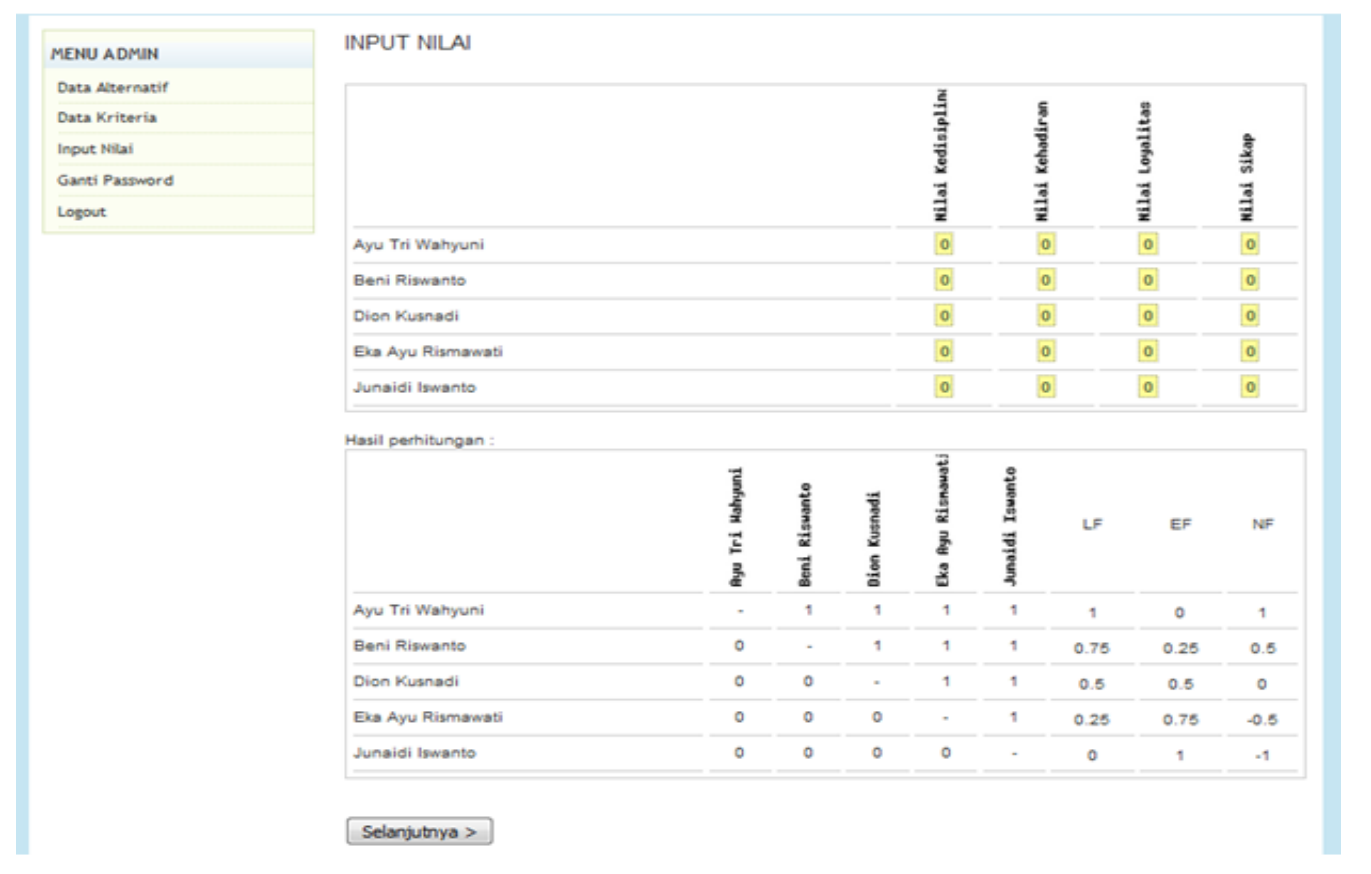

\subsection{Pengujian Aplikasi}

Gambar 9. Tampilan Form Input Nilai

Dalam hal ini akan dilakukan pengujian terhadap sistem aplikasi yang telah dibangun. Adapun metode dalam hal pengujian sistem menggunakan metode Black Box. Dengan menggunakan metode ini diharapkan dapat memaparkan kelayakan kinerja dari sistem. Pada Tabel 5 merupakan hasil pengujian sistem aplikasi yang dibangun.

Tabel 5 Pengujian Kelas Uji Sistem Input Data

\begin{tabular}{|c|c|c|c|c|}
\hline No & Skenario Pengujian & Hasil Yang Diharapkan & Hasil Pengujian & $\begin{array}{l}\text { Kesimpul- } \\
\text { an }\end{array}$ \\
\hline 1 & Input Data Kriteria & $\begin{array}{l}\text { Sistem dapat memasukan } \\
\text { data kriteria. }\end{array}$ & $\begin{array}{l}\text { Sistem dapat memasukan } \\
\text { data kriteria. }\end{array}$ & Valid \\
\hline 2 & Hapus Data Kriteria & $\begin{array}{l}\text { Sistem dapat menghapus } \\
\text { data kriteria }\end{array}$ & $\begin{array}{l}\text { Sistem dapat menghapus } \\
\text { data kriteria }\end{array}$ & Valid \\
\hline 3 & Tampil Data Kriteria & $\begin{array}{l}\text { Sistem dapat menampilkan } \\
\text { data kriteria }\end{array}$ & $\begin{array}{l}\text { Sistem dapat menampilkan } \\
\text { data kriteria }\end{array}$ & Valid \\
\hline 4 & $\begin{array}{l}\text { Data kriteria bersifat } \\
\text { dinamis }\end{array}$ & $\begin{array}{l}\text { Sistem dapat mengelola data } \\
\text { kriteria yang tidak terbatas }\end{array}$ & $\begin{array}{l}\text { Sistem dapat mengelola data } \\
\text { kriteria yang tidak terbatas }\end{array}$ & Valid \\
\hline 5 & Notifikasi & $\begin{array}{l}\text { Sistem dapat memberikan } \\
\text { informasi apabila terjadi } \\
\text { kesalahan sistem }\end{array}$ & $\begin{array}{l}\text { Sistem tidak dapat } \\
\text { memberikan informasi } \\
\text { apabila terjadi kesalahan } \\
\text { sistem }\end{array}$ & Valid \\
\hline 6 & Input Data Alternatif & $\begin{array}{l}\text { Sistem dapat memasukan } \\
\text { data Alternatif. }\end{array}$ & $\begin{array}{l}\text { Sistem dapat memasukan } \\
\text { data Alternatif. }\end{array}$ & Valid \\
\hline 7 & Hapus Data Alternatif & $\begin{array}{l}\text { Sistem dapat menghapus } \\
\text { data Alternatif }\end{array}$ & $\begin{array}{l}\text { Sistem dapat menghapus } \\
\text { data Alternatif }\end{array}$ & Valid \\
\hline 8 & $\begin{array}{l}\text { Tampil Data } \\
\text { Alternatif }\end{array}$ & $\begin{array}{l}\text { Sistem dapat menampilkan } \\
\text { data Alternatif }\end{array}$ & $\begin{array}{l}\text { Sistem dapat menampilkan } \\
\text { data Alternatif }\end{array}$ & Valid \\
\hline 9 & $\begin{array}{l}\text { Data Alternatif } \\
\text { besifat dinamis }\end{array}$ & $\begin{array}{l}\text { Sistem dapat mengelola data } \\
\text { Alternatif yang tidak } \\
\text { terbatas }\end{array}$ & $\begin{array}{l}\text { Sistem dapat mengelola data } \\
\text { Alternatif yang tidak } \\
\text { terbatas }\end{array}$ & Valid \\
\hline 10 & Notifikasi & $\begin{array}{l}\text { Sistem dapat memberikan } \\
\text { informasi apabila terjadi } \\
\text { kesalahan sistem }\end{array}$ & $\begin{array}{l}\text { Sistem tidak dapat } \\
\text { memberikan informasi } \\
\text { apabila terjadi kesalahan } \\
\text { sistem }\end{array}$ & Valid \\
\hline
\end{tabular}


Langkah selanjutnya akan dilakukan proses perhitungan prosentase nilai kinerja sistem aplikasi yang dibangun. Dalam melakukan proses perhitungan prosentase, menerapkan rumus perhitungan dengan rumus sebagai berikut.

Nilai Kelayakan Sistem $=($ Jumlah Valid $/$ SSkenario Pengujian $) \times 100$

Berdasarakan rumus perhitungan kelayakan sistem yang telah dipaparkan, maka nilai kelayakan sistem adalah sebagai berikut.

$$
\begin{aligned}
\text { Nilai Kelayakan Sistem } & =(26 / 26) \times 100 \\
& =100 \%
\end{aligned}
$$

Sehinga dapat disimpulkan bahwa dengan melakukan pengujian kelayakan sistem, dengan menggunakan jumlah skenario pengujian sebanyak 26 butir uji, hasil valid 26. Maka nilai kelayakan sistem aplikasi pendukung keputusan dalam melakukan penentuan penerima insentif sebesar $100 \%$.

\section{KESIMPULAN DAN SARAN}

\subsection{Kesimpulan}

1. Sistem Pendukung Keputusan Dalam Menentukan Calon Penerima Insetif yang dibuat sudah sesuai dengan proses analisa dengan metode PROMETHEE. Hal tersebut dibuktikan dengan hasil proses perhitungan pembobotan sampai dengan memperoleh nilai pada setiap alternatif, dimana hasil sistem sama dengan proses analisa perhitungan secara manual.

2. Sistem pendukung keputusan yang telah dibuat, dengan menggunakan jumlah skenario pengujian sebanyak 26, hasil nilai valid sebanyak 26. Maka hasil nilai kelayakan sistem dari aplikasi yang telah dibangun sebesar $100 \%$.

3. Hasil perhitungan menggunakan metode PROMETHEE pada kasus penentuan calon penerima insentif, menghasilkan data Karyawan yang layak menerima insentif yang paling tinggi Eka Ayu Rismawati dengan bobot net flow yang paling besar yaitu 0,5.

\subsection{Saran}

1. Secara umum aplikasi pendukung keputusan yang dibuat sudah mampu memberikan alternatif keputusan bagi pihak perusahaan dalam membantu menetukan karyawan yang layak mendapatkan insentif. Akan tetapi didalam sistem masih terdapat beberapa sistem validasi yang tidak maksimal, sehingga disarankan agar pengembangan aplikasi ini dapat ditingkatkan dalam hal sistem validasi data.

2. Sebaiknya pengguna atau admin yang menjalankan aplikasi ini adalah orang yang telah mengerti tentang cara menjalankan atau mengoperasionalkan komputer. Hal tersebut penting karena pada aplikasi ini terdapat beberapa alur atau prosedur yang mengharuskan pengguna mengerti tentang cara menggunakan komputer.

\section{DAFTAR PUSTAKA}

Fathansyah. (2012). Basis Data - Buku Teks Ilmu Komputer Basis Data (Edisi Revisi). Bandung: Informatika.

Harry Budiharjo S, H. S. (2015). Perencanaan Sistem Pendukung Pengambilan Keputusan Penerimaan Taruna Dengan Metode Promethee (Studi Kasus Seleksi Taruna AKMIL). Seminar Nasional Informatika 2015 (semnasIF 2015) (pp. 147-155). Yogyakarta: UPN "Veteran" Yogyakarta, 14 November 2015.

Hidayat, R. P. (2013). Sistem Pendukung Keputusan Pemilihan Guru Berprestasi Menggunakan Metode Promethee. Jurnal Sains Dan Seni Pomits Vol. 2, No.1, ISSN. 2337-3520 (2301-928X Print) , 1-6.

Turban, E. (2005). Decicion Support Systems and Intelligent Systems. Yogyakarta: Penerbit Andi. 